Article

\title{
A Sectoral Micro-Economic Approach to Scenario Selection and Development: The Case of the Greek Power Sector
}

\author{
Alexandros Flamos \\ Department of Industrial Management and Technology, University of Piraeus, Karaoli \& Dimitriou 80, \\ Piraeus 18534, Greece; aflamos@unipi.gr; Tel.: +30-210-414-2460 \\ Academic Editor: Robert Lundmark \\ Received: 14 November 2015; Accepted: 19 January 2016; Published: 27 January 2016
}

\begin{abstract}
Generating policy-relevant scenarios is instrumental for understanding and developing policy measures. These are especially relevant to the power sector. Practitioners have been working on policy-relevant scenarios for the ex-ante assessment of policy measures in a meaningful way for end-users related to climate change mitigation and adaptation strategies. This paper presents a method for generating such policy relevant scenarios by focusing on the actor-contingent elements of the scenarios, i.e., the developments that are within the control of system actors to change or bring about. Several scenario techniques focusing on systematic-formalized or quantitative approaches have been published on this front over the past few years. Here, we introduce a methodology that is best suited for the assessment of the expected effect of different policy measures on the involved stakeholders' behavior as well as for the analysis of the interactions between different policy measures as reflected on their impact on the strength and direction of the provided incentives. The applicability of our methodology is demonstrated for the case of the Greek power market. It was further evaluated in view of the challenges related to the issues of generation capacity adequacy and increased fiscal deficit. The strategic implications of the proposed approach concern the demonstration of the benefits from adopting a policy assessment methodology that focus on stakeholder expectations and interactions.
\end{abstract}

Keywords: actor-based modeling and analysis; generation capacity adequacy; power market; policy assessment; scenario development

\section{Introduction}

In this paper, a semi-quantitative method to generate policy-relevant scenarios for the ex-ante assessment of policy measures with a particular emphasis on the power sector is presented. The approach is mainly based on the context of a project co-financed by the European Commission's Seventh framework Programme for Research and Technological Development (European Commission (EC) Seventh Framework Package (FP7) Research and Technological Development (RTD) Programme), entitled "Assessment of Policy Interrelationships and Impacts on Sustainability in Europe (APRAISE)".

This method aims to overcome the shortcomings of most common scenario techniques. As such, systematically-formalized scenario techniques are based on identifying the most significant driving forces that affect future trends and then proposing a small number of scenarios that explore different combinations of these driving forces. In contrast, the quantitative approach of Groves and Lempert [1] first creates a large amount of scenarios and then the scenario space is mechanically partitioned into clusters of distinctly differentiated performances of the policy measure under examination.

We define the term "policy-relevant scenarios" as the scenarios that are most important to the choices that the decision-makers face. The identification of the policy relevant scenarios requires 
the distinction of the important, viz., the consequential scenarios, from the ones that can safely be excluded from the policy assessment process. Under this perspective, the term can be further explained as follows:

- In case the adopted approach aims to first develop and then quantify a small number of narratives for future developments, policy-relevant scenarios are the ones that-despite their small number-can shed light on the conditions that constitute threats or opportunities for the realization of the corresponding goals of the policy measure.

- In case the adopted approach aims to first quantify a large number of plausible scenario parameter combinations and then develop the future narratives, policy-relevant scenarios are the ones that correspond to the thresholds between different regions of policy performance, i.e., the states of the world where the policies have significantly different performance.

The main limitation of basing a policy assessment exercise on a small set of narrative-rich scenarios comes from the cognitive biases that hinder any attempt to imagine potential future surprises and structural breaks. Wright and Goodwin [2] present a series of weaknesses of this approach including cognitive and motivational biases, falsely perceived boundaries of uncertainty, as well as inappropriate attributions of causality. In fact, the term policy-relevant scenario was coined by Groves and Lempert presented in [1] to avoid the case where story lines are developed before running the quantitative model. As a result, either the quantified paths put aside the story lines' analysis of the key driving forces or the resulting scenarios dominate the analysts' point-of view because it is well documented that judgments concerning the probability of a scenario are unrelated to its actual likelihood [3].

Creating scenarios by aggregating a large number of scenario parameter combinations implies the assumption that the dominant uncertainty is parametric, i.e., we have a good model of the future structure of the system, but we don't know the future value of its parameters. However, this assumption is quite strong for most cases. As a remedy, one can focus on the aspects of the future that are expected to be consistent and stable. The proposed approach is based on the notion that the actor-contingent elements of a scenario, i.e., the developments that are within the power of system actors to change or bring about, if they so choose, can form the foundation of the scenario development process [4]. As a result, the scenario development begins with the identification of the actors that are affected by the policy instruments under study or the behavior of those who may support or impair the instruments' effectiveness. The factors and events that are most influential on the actors' decision-making process and criteria are indeed the ones with the greatest influence on the evolution of a policy instrument's impact over time. Thus, these factors and events define the parameters that should constitute the scenarios utilized for the policy instrument's assessment.

The remainder of this paper is organized as follows: Section 2 gives a concise description of the proposed methodology for scenario development as well as supporting tools. Section 3 describes the policy challenges identified in the Greek power sector, which have shaped the research questions to be addressed through the scenario generation. Furthermore, it presents the implementation details and the suggestions on how policy makers can derive meaningful parameters for appropriate scenario development and provides some guidelines for the operationalization of the proposed methodology as well as its integration into existing scenario development approaches. The paper will close with observations about the strengths and weaknesses of this new approach and directions for further research in this area.

\section{Methods}

The majority of scenario development approaches are based on three (3) conceptual components:

1) The baseline scenario of both the exogenous parameters and the policy measures. The baseline scenario answers the question of which scenario parameter values are in accordance with the current trends and outlooks. Taking the contemporary status of knowledge of trends and 
developments as a starting point, this scenario is then used to paint a future in which no new developments or actions are assumed.

2) The scenario space that encompasses all parameters and the different combinations that differentiate the scenarios under development. Because many parameters can be generated, one important task in scenario generation is to identify either a priori or after the scenario evaluation a manageable subset containing the most influential scenarios.

3) The exploratory scenarios that allow the researchers to evaluate a policy measure under different contexts and conditions.

Borjeson et al. [5] present a typology of scenario development techniques based on different types of scenarios. Based on this typology, the approach presented in this paper develops explorative strategic scenarios:

- The explorative scenarios are defined by the fact that they respond to the question: What can happen? The aim of explorative scenarios is to explore situations or developments that are regarded as possible-usually from a variety of perspectives. Typically, a set of scenarios are worked out to span a wide range of possible developments. In this respect, explorative scenarios resemble what-if scenarios, but the explorative scenarios are elaborated with a long time-horizon to explicitly allow for structural, and hence more profound, changes.

- Strategic scenarios incorporate measures at the hand of the intended scenario user to cope with the issue at stake. The aim of the strategic scenario is to describe a range of possible consequences for strategic decisions. Strategic scenarios focus on internal factors (i.e., factors that scenarios can possibly affect), but they also consider external aspects. They describe how the consequences of a decision can vary depending on which future development unfolds. In these scenarios, the goals are not absolute; rather, target variables are defined.

Furthermore, van Notten et al. [6] categorizes scenario development techniques by placing them on a field, where the vertical dimension corresponds to the continuum from qualitative to quantitative analysis and modeling methods, and the horizontal axis to a continuum from formal to heuristic approaches. Under this perspective, the approach presented in this paper is a formal approach that combines qualitative and quantitative inputs to derive scenarios.

The proposed approach builds on Hughes [7], who regards scenario development as a process where the behavior of and the interrelations between self-interested actors dictate the evolution of scenarios. In this way, technology change and adoption is regarded as an outcome of the balance of power and interests between the involved actors. Accordingly, the proposed approach starts with the premise that the dynamics in a given market are driven mainly by the choices of the micro-level actors involved. An actor represents a group of relatively homogeneous stakeholders. Homogeneity implies that the actors in the identified group have common interests and a common set of options at their disposal. Consequently, the scenario development process begins with the identification of the actors affected by the policy instruments under study or the behavior of whom they may support or impair the instruments' effectiveness. The interactions and relationships between the actors are also considered; the actors' mutual dependence is illustrated both in cases of different actors that belong to the same value chain and in cases of actors that compete with each other for the same resources or for the same market.

At the same time, the most influential factors on the actors' decision-making process and criteria are the ones with the greatest influence on the evolution of a policy instrument's impact over time. Thus, these factors define the parameters that should constitute the scenarios utilized for the policy instrument's assessment. As an example, energy resource and energy technology actors include owners, developers and investors in energy resources and energy-related capital stock. Their decisions are driven by their key corporate goals such as entry into new markets, profit opportunities through portfolio effects or risk minimization, as well as compliance with safety and environmental standards. Their decisions are affected mainly by the uncertainty about government regulations and about changes 
in energy technologies and prices as well as macroeconomic conditions and availability of capital. Based on the aforementioned line of thought, these parameters should be included in the scenario parameter space when assessing policy instruments-the scope of which includes the power sector.

The definition of different possibilities for the actors' behavior that may constitute threats or opportunities for the achievement of the policy instruments' goals-as well as their correspondence to the values of the scenario parameters inducing such behavior-can assist the identification of a set of scenarios. These scenarios are cross-cutting to the policy pathways for the long-term developments that correspond to either significant policy risks (i.e., least favorable outcomes) or policy opportunities (i.e., most favorable outcomes).

The methodology begins by identifying the actors involved, their goals, the alternative options that the actors have at their disposal to pursue their goals, as well as the criteria they use to adopt these options. The actors' goals indicate what they wish to achieve and which changes they would like to realize (or what they would like to maintain). The gap between their goals and the perceived existing or expected situation determines the nature and direction of the reaction. Furthermore, it is assumed that actors will act according to the options they have at their disposal, i.e., their behavior corresponds to selecting one or more of the options that are available to them. Some options may correspond to pure choices of strategy while other options are technology choices.

The selected scenario parameters should have a direct influence either on the evaluation of the actors' options or on the dynamics that govern their inter-relationships. With the help of the previous steps, a table summarizing each actor's perceptions in reference to a number of features (goals, threats, available options, criteria for option selection, and factors affecting option value) can be completed. The definition of each actor's features can enable the definition of different possibilities concerning the actors' behavior.

Furthermore, the individual actor models are connected in a network form where a subset of a model's inputs is contingent on the results of another. Variations of the Dynamic Actor Network Analysis [8] can be utilized to explore the interactions between the actors. By combining elements from stakeholder analysis and strategic decision analysis, one can make it explicit how (to the eyes of the analyst) each of the actors involved perceive the system in terms of what is desirable, what actions are possible, what exogenous influences are to be expected, and how these aspects are causally related.

The fact that the proposed approach benefits from stakeholder analysis means that it can be complemented with any of the existing methodologies that combine scenario development with participatory processes using multiple stakeholders as participants. Indicatively, the modified Delphi method of Varho and Tapio [9] can be utilized not only for eliciting consensus-based scenarios for uncertain parameters but also for identifying plausible reactions of the relevant actors to unfolding events in the future.

Papadelis et al. [10] provides an argument and a conceptual framework for the convergence between policy assessment evaluation and business strategy assessment models as a way to assist regulators in deriving effective policy assessment techniques. Under this line of thought, the goals of the policy instruments under study should be translated into desirable actor behavior. As a result, the determining factors for the success of the policy instruments can be mapped on the factors that determine the expected behavior in the actors affected by the instruments.

To quantitatively define the policy-relevant scenarios, we build on Kwakkel et al. [11]. According to this approach, an ensemble of model runs is created based on the uncertainties as perceived by the actors involved. This ensemble is then screened to identify runs of interest. The extension of this approach to the proposed actor-based scenario development technique is based on a random parameter sampling and subsequent actor options' valuation. This approach highlights the thresholds defining different actors' behaviors, i.e., the conditions under which the perceived value of the desirable options-from the policy makers' point of view-becomes smaller than the value of the non-desirable ones. These thresholds correspond to different regions of policy performance, i.e., the states of the world where the policies have significantly different performance. Thus, they reduce the number of scenarios to a number that makes them easy to explain and present. 
The outcome of this process is the threshold values of the exogenous scenario parameters that change the ranking of the policy instruments under study as well as the scenario parameters that correspond to significant policy risks and opportunities. An additional advantage of this approach is that one does not need to run different scenarios using a big, integrated model. Rather, one can use a series of smaller ones, each one representing the business logic and decision making process of an actor. These individual models can run in parallel to take advantage of horizontal scaling techniques.

Although the actual models used for the actor behavior is out of this paper's scope, a brief highlight of the widest spread class of models is beneficial here. These models encapsulate the actors' decision rules in the form of a discrete choice model. From the moment they first appeared in the literature [12], the discrete choice models have been used to describe behaviors that can be summarized as choices between alternative options. The underlying rule of these models is that an actor will choose the option that maximizes his/her utility function. As a utility function, either the well-known Net Present Value (NVP) or the Risk Adjusted Return on Capital can be used [13].

A quantitative or semi-quantitative model for the options' valuation should also be in place. In the simplest case, one needs only a prescriptive model of the value assigned to each option under different exogenous conditions and risk measure constraints. In the most encompassing case, the modeler should also consider the effect of the actors' expectations as well as the networks formed by them. This requirement makes agent-based models a natural fit for the proposed method:

1. Agent-based models are driven by actor responses under different conditions; hence, identifying the most consequential conditions can narrow the models' exploration space.

2. The same methods (algorithms and implementation) that actors use to make decisions in a given agent-based model can be employed for option evaluation.

Wright and Goodwin [2] provide a useful approach according to which one can work backwards from the policy objectives rather than moving forward through causal chains to arrive at scenarios as in conventional scenario planning. This is accomplished through the following steps:

1) Elucidation of policy goals;

2) Identification of the factors/indicators that determine the extent to which the goals are achieved;

3) Identification of the drivers or interactions of drivers that have the greatest impact on the actual values of the aforementioned factors;

4) Construction —-through backward analysis—of exploratory scenarios consisting of events and conditions that correspond to the least favorable values of the aforementioned factors.

It is straightforward to embed the approach presented in this paper in step 3.

\section{Application and Results}

The objective of the case study is to demonstrate the proposed approach. In particular, it will show where the methodology focuses so as to identify parameters and trends of policy-relevant scenarios.

\subsection{Identifying the Policy Challenges}

Defining the research questions of the analysis helps narrow it down to specific assumptions that can be confirmed or falsified through modeling experiments. Furthermore, they help assess specific aspects of the relevant policy instrument's performance and discover ways to improve it. The research questions for the implementation presented here were shaped by the challenges identified in the impact assessment of the EC Communication on renewable energy policy [14] presented on 6 June 2012 (COM/2012/271) as well as in the Green Paper on "A 2030 framework for climate and energy policies" [15]. This was adopted by the European Commission on 27 March 2013.

In particular, the EC Communication on the renewable energy sources-the electricity (RES-E) policy -identified the following key challenges for the European Union (EU) RES-E energy sector: 
1) The viability of the provided financing incentives in light of the economic turndown [16] and the budgetary problems of Member States and businesses that create difficulties in mobilizing funds for long term investments.

Countries like Spain or Greece have been facing a feed-in tariff deficit [17] and consequently are resolving to cut subsidies, retroactive revenue taxes, tariff reductions and halts to new renewable energy projects. This makes national and international investors cautious about investing in capital-intensive energy markets, and in particular in the policy-dependent renewable energy sector.

2) The consistency of the market mechanisms currently in effect with the enhanced RES-E integration on the EU wholesale electricity markets.

The rapid increase in power generation from RES (Renewable Energy Sources) has been accompanied by an equally rapid decrease in the wholesale price of electricity. This is because the feed in tariff is offered outside of the wholesale electricity market, and the market energy price is not influenced by the tariff. In contrast, it is influenced by the retail price faced by the end consumers. In fact, in times of high RES-E in-feed and low demand, the power market reacts with bids beneath the variable costs to avoid ramping-down base load power plants, which are expensive to restart. This phenomenon has resulted in negative prices in the German electricity market. In Greece, where negative prices are not allowed, zero wholesale prices are an increasingly frequent condition in 2012, especially in 2013.

The Green Paper on "A 2030 framework for climate and energy policies" identifies additional challenges the EU and global energy markets will face in developing unconventional gas.

Based on the abovementioned challenges, one can devise the following research questions as well as their specialization according to the actor-oriented perspective (Table 1). These questions should shape the policy-relevant scenarios to be developed.

Table 1. Perceiving the policy challenges through an actor-oriented point of view.The first column contains the policy challenges that form the respective policy scenarios and need to be properly addressed. The second one lists the research questions shaping the policy-relevant scenarios. Finally, the third column exhibits the actor-oriented point of view envisaging the scope of perception of the policy challenges to be addressed and of the policy scenarios to be developed.

\begin{tabular}{lll}
\hline \multicolumn{1}{c}{ The Policy Challenges } & \multicolumn{1}{c}{ The Research Questions } & The Actor-Oriented Perspective \\
\hline $\begin{array}{l}\text { The viability of the provided } \\
\text { financing incentives for RES-E } \\
\text { deployment. }\end{array}$ & $\begin{array}{l}\text { How robust is the policy instrument's } \\
\text { performance with respect to different } \\
\text { macroeconomic conditions that may } \\
\text { hinder public finance support? }\end{array}$ & $\begin{array}{l}\text { Under which conditions is an } \\
\text { investment in RES-E profitable } \\
\text { under a scheme of progressively } \\
\text { reduced public finance support? }\end{array}$ \\
\hline $\begin{array}{l}\text { The consistency of the market } \\
\text { mechanisms currently in effect. }\end{array}$ & $\begin{array}{l}\text { Which are the possible effects of } \\
\text { policy instruments promoting } \\
\text { renewables to the fossil-fueled part of } \\
\text { the energy generation mix? }\end{array}$ & $\begin{array}{l}\text { What are the interactions and } \\
\text { monetary flows between the } \\
\text { renewable and the } \\
\text { fossil-fueled generators? }\end{array}$ \\
\hline $\begin{array}{l}\text { Development of global } \\
\text { energy markets. }\end{array}$ & $\begin{array}{l}\text { How robust is the policy instrument's } \\
\text { performance with respect to different } \\
\text { developments in recourses' prices? }\end{array}$ & $\begin{array}{l}\text { What is the sensitivity of the } \\
\text { expected value of different } \\
\text { technology options to variations in } \\
\text { fuel prices? }\end{array}$ \\
\hline
\end{tabular}

The next subsection will present the implementation steps to translate the aforementioned questions into scenarios that can feed a qualitative or quantitative policy assessment process.

\subsection{Implementation Details}

The implementation of the proposed approach requires the identification of the involved actors, their goals and the options they have at their disposal to pursue them. Accordingly, in the Greek electricity market, the following actors can be identified:

1) Providers of centralized power are further distinguished according to the nature of their resources, i.e., fossil fuels or renewable sources. 
2) Providers of decentralized power, especially small photovoltaic (PV) farms and owners of buildings with rooftop PV installations ( $<10$ kilowatt peak).

The system operator represented by the Special RES account. RES-E remuneration through Feed in Tariff (FITs) is paid to the RES producers through the Special RES account that was established by article 40 of Law 2773/1999 and is managed by the Hellenic Electricity Market Operator (HEMO). The outflows of the Account are the RES-E FIT payments, whereas its main inflows are the amounts paid to the RES-E suppliers for each megawatt hour (MWh) fed in the system at the System Marginal Price (SMP) as well as the RES-E levy that covers the remaining needed amount. This is paid directly by the final consumers. The RES-E levy is practically the difference of FITs minus the SMP or the difference between FITs and the average variable cost in the case of the islands. A specificity of the Greek electricity system is the fact that $8.9 \%$ of its consumption takes place in the non-interconnected island electricity networks, which cover more than $90 \%$ of their demand through oil-fueled units. Because FITs are generally higher than the SMP. The HEMO faces a deficit that must be paid by the electricity consumers through the RES-E levy. The annual deficit is equal to:

$$
\sum_{t=1}^{n} \sum_{h=1}^{8760}\left(S M P_{h}-F I T_{t}\right) \cdot R E S_{h}^{t}
$$

where:

$S M P_{h}$ is the system marginal price during the hour $h$,

FIT $_{t}$ is the feed-in tariff for the technology $t$,

$R E S_{h}^{t} \quad$ is the RES-E production (MW) during hour $h$ by technology $t$.

The deficit is covered through the RES-E levy, and its level is determined by the Greek Ministry of Development.

The providers of centralized, fossil-fueled power production can be regarded as profit-maximizing actors. Their decisions are subject to some risk measure constraint and are usually related to liquidity risk. Two adverse conditions can be identified for the achievement of this goal: (a) when due to market developments or regulatory interventions a plant's cost position worsens in relation to its current and potential competitors and (b) the market is characterized by overcapacity. A relevant case of the first condition can be found in the widening of the spread between the natural gas and the coal prices which, in combination with low permit prices in the EU European Trading System (ETS) during 2012 and 2013, yielded a substantial incentive to generate electricity from coal-fueled plants rather than gas-fueled ones. Recent announcements by European utilities highlight the effects of the low gas-fueled plant generation margins. From a market overcapacity and asset value perspective, they also indicate significant action in response in the form of mothballing, closures, strategic re-direction and occasionally asset sales. The following is a summary of utility announcements in Q1 2013:

- The French Energy Company Gaz De France Suez (GDF Suez) wrote down 2 billion $€$ worth of uneconomic gas plants in Europe. GDF recently took another 1.3 Gigawatt (GW) of capacity offline in addition to the $7.3 \mathrm{GW}$ it has mothballed or closed since 2009.

- E.ON S.A. announced in January that it has scheduled $10 \mathrm{GW}$ of thermal assets to be decommissioned between 2012 and 2015.

- Centrica only broke even on its portfolio of United Kingdom's (UK) gas-fired generation assets in 2012 and expects a $£ 100$ million loss in 2013. In response, it has announced the mothballing of Kings Lynn power station from April 2013 because it sees no improvement in spark spreads in the medium term. Centrica has re-configured the Peterborough, Brigg and Roosecote Combined Cycle Gas Turbines (CCGTs) to enable them to run in open-cycle mode.

- Scottish and Southern Energy (SSE) has announced it will undertake extended maintenance at its 760 MW Keadby and 688 MW Medway plants in the UK. It expects them to be offline for at least a year. 
- Barking Power is idling capacity at its 1 GW CCGT outside London on the expectation that it will be unprofitable for the next couple of years.

- DONG announced a 27 percent write down on its Severn CCGT in the UK. It has only been able to operate its recently commissioned Dutch Enecogen CCGT plant at below 10\% load factor. DONG's 2013 strategic statement declared that it was pulling out of further investment in gas plants.

This observation leads to a first important scenario parameter: the spread between natural gas and coal prices. At the same time, this spread reflects the price threat of the fossil-fueled generators, and the volume threat should also be considered. In particular, according to the current regulatory framework, all production from RES-E must be fed into the electricity grid. Conventional generation units (i.e., lignite, natural gas and large hydropower) cover the remaining (hereafter residual) demand. As a result, RES-E generation can be regarded as a negative demand that affects the residual load's levels and profile. To gain a better perspective on the relationship between the electricity demand and RES-E production in the Greek electricity market, one can plot two time series together; Figure 1 depicts the relevant data for 2013.

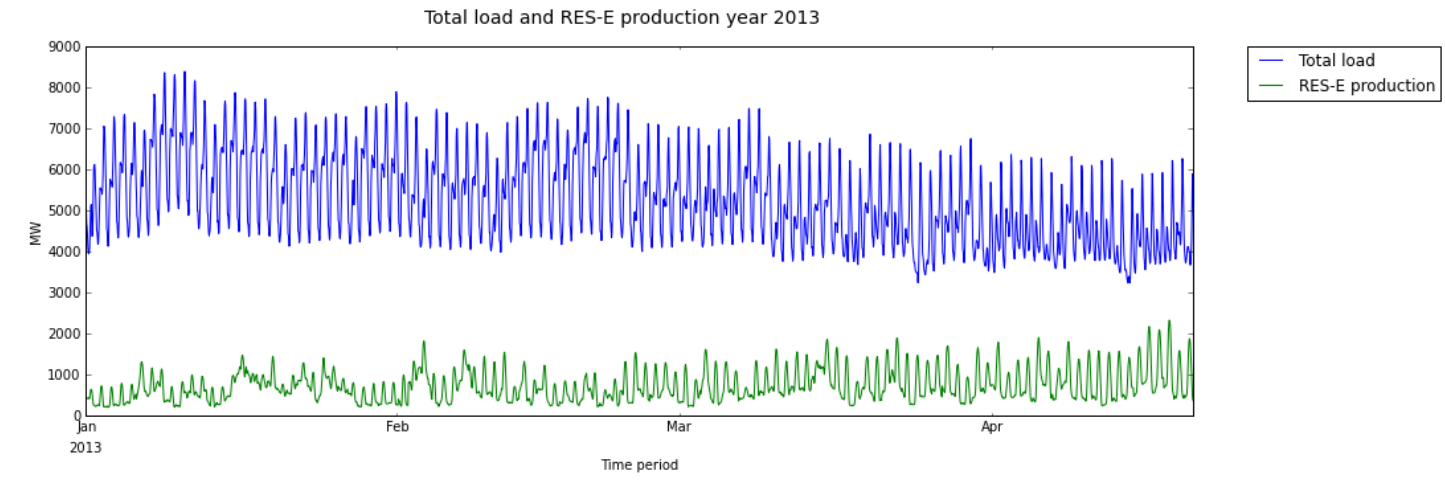

Figure 1. Demand and RES-E production for the year 2013: Plotting the time series electricity demand in the Greek electricity market for the year 2013 along with the respective RES-E production for the same year gives a clear perspective on how their relationship affects the residual load's levels and profiles in Greece. Both demand and production ( $y$-axis) are in megawatts while time ( $x$-axis) is in months.

One question to be explored through scenario generation concerns the way the plot of the previous figure could change if RES-E penetration reached $20 \%$ or $40 \%$ coverage on an annual basis. To this end, one must scale the RES-E generation profiles according to the present data. Here, the data of March 2013 was chosen as the starting point. The results of the scaling exercise are illustrated in Figure 2.

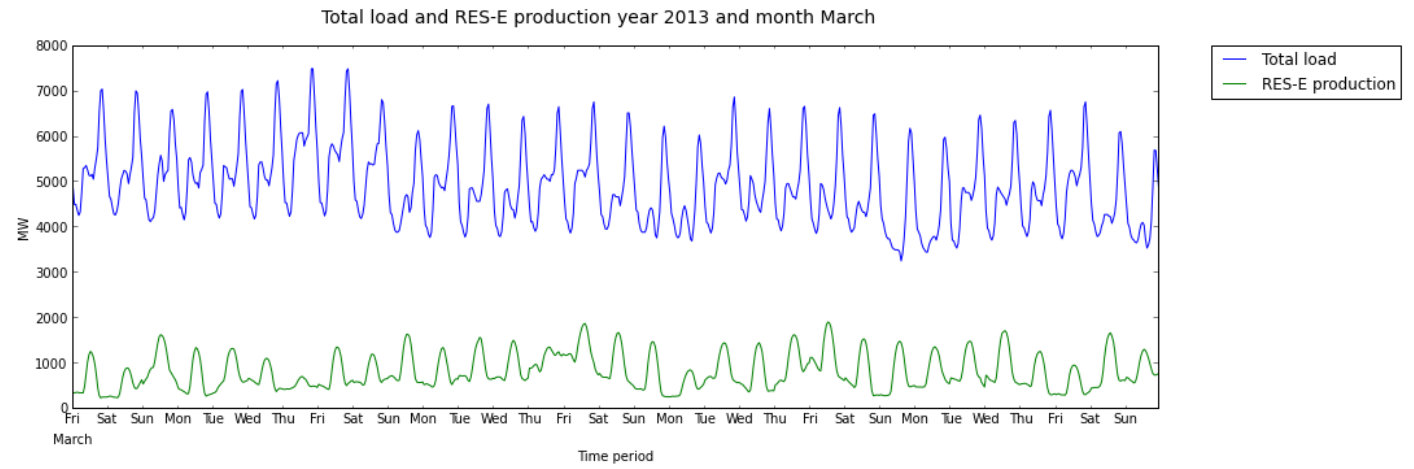

Figure 2. Demand and RES-E production for March 2013-both demand and production (y-axis) are again in megawatts while time ( $x$-axis) is this time in days.

It is clear that at certain time periods the demand left to be serviced by the non-RES technologies (henceforth the residual load) is significantly low. This pushes out the wholesale market capacity-this 
is nevertheless needed in other periods (i.e., periods with high total demand and low RES-E output). As a result, the residual load is another influential parameter that must be included in the scenario space.

Actors in a system may have opposite views on the same exogenous driver. Offsetting fossil-fueled generation via RES-E generation is a threat for fossil-fueled plants and a real economic benefit for the system. This should be avoided due to natural gas imports. This effect is stronger when the price of natural gas is higher as is the case in reality (Figure 3).
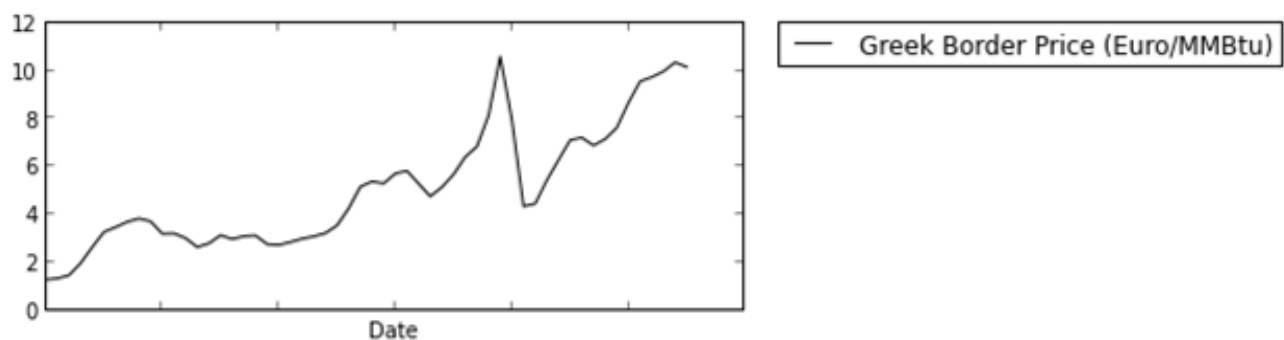

Figure 3. Evolution of the Greek border price for natural gas imports: The figure depicts the rapid increase in the price of the natural gas imports versus time for the case of Greece.

Masini and Menichetti [18] surveyed the factors that influence the decisions regarding renewable energy investments. Their study demonstrates the importance of clear policy signals in driving investment. Investors attach a high premium to the certainty of the investment returns. A predictable long-term policy commitment is likely to be more effective than excessive short-run fiscal incentives to attract investment. In addition, they found that investors consider tariff size and contract duration of feed-in-tariffs to have nearly identical importance.

Providers of decentralized renewable energy sources (RES) face threats that are mainly related to the regulatory changes. In February 2012, Greece announced cuts in solar subsidies to ensure the viability of the financing mechanism to secure the operation of the units already installed and to develop new ones. The feed-in tariff was cut by $12.5 \%$ to 0.292 euro per kilowatt hour $(€ / \mathrm{kWh})$ for solar coming online from February 2012. This generated more than 100 kilowatts. Later on, Greece cut feed-in tariff rates roughly 44\% for solar photovoltaic (PV) plants installed after 1 February 2013. Grid-tied ground-mounted PV plants smaller than 100 kW installed from 1 February 2013 to 31 January 2014 will have their rates reduced to $0.095 € / \mathrm{kWh}$ with plants larger than $100 \mathrm{~kW}$ receiving $0.120 € / \mathrm{kWh}$. Policy developments can be partially correlated with macroeconomic developments. The example of FIT cuts is a reflection of the fact that subsidy support is dependent on robust public finances.

In terms of behavior modeling, a basic difference between centralized (including large wind farms) and decentralized (mainly small PV projects) is the size of investment and the corresponding type of investors. Large investments are dominated by institutional investors showing long-term engagement and only subtle changes in attitude. By contrast, a large number of individuals (e.g., farmers or building owners) can engage in PV investments; they are especially attracted by high FITs, but they are also subject to herd behavior when the policy support seems to weaken.

Another relevant aspect is the interplay between the SMP and the RES-E production. What one should generally expect is that the merit order effect would cause the average System Marginal Price (SMP) to fall with an increasing RES-E production because the latter will shift the intersection of the residual demand with the supply curve to the left. Figure 4 presents the evolution of the monthly average SMP in the Greek power market from 1 January 2008 to 30 September 2013.

Monthly average of the SMP for the period from 1 January 2008 to 30 September 2013: These two time periods are of interest regarding the divergence of the average SMP from the identified trend. The first one lies between the 1 September 2011 when the Greek Ministry of Finance introduced a special consumption tax on natural gas that was also applied also to electricity production and the 18 January 2012, when the Regulatory Authority for Energy of Greece (RAE) with the regulatory decision 1528/2011 excluded the tax from the electricity production. The second period was from June 
to August 2012). Although this price disruption complies with the expected load increase due to high cooling demand in South Europe during summer, it is quite distinct from the respective time behavior during the three previous years. This distinction reflects the scarcity of hydro after two successive years of high reservoir levels as well as the higher natural gas prices.

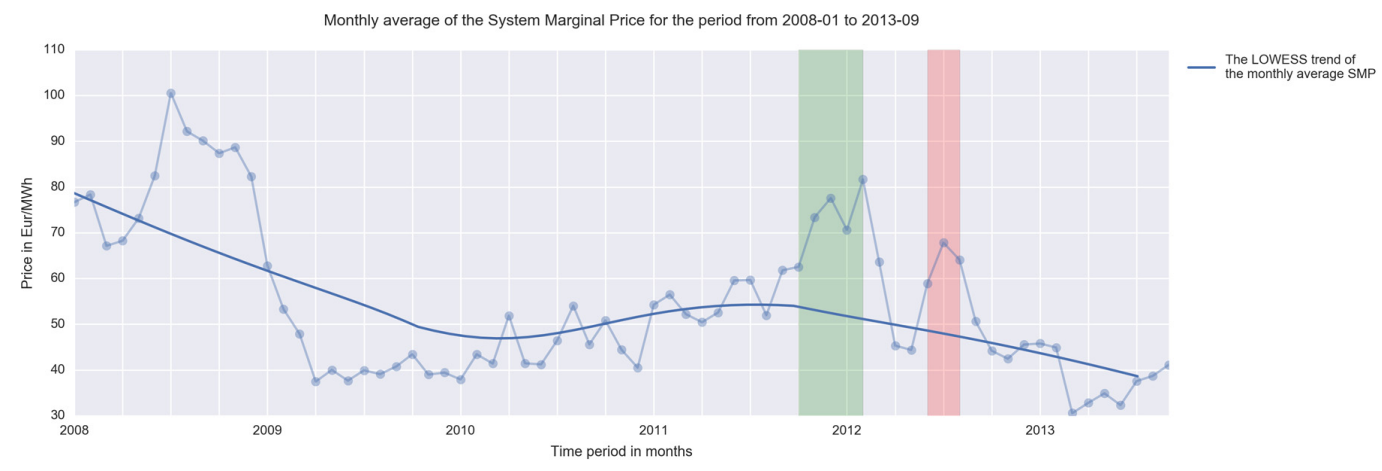

Figure 4. Evolution of the monthly average SMP in the Greek power market from 1 January 2008 to 30 September 2013-SMP ( $y$-axis) is in Euro/MWh, and time ( $x$-axis) is in years.

Thus far, we have highlighted the nature and role of the actors' options. Options can be artifacts, and they correspond to the power generation technologies available for the market actors to invest on or for the policy makers to support. Options can also be business strategies or policies in which case they correspond to investment or disinvestment decisions or to decisions of reinforcing or relaxing the support scheme for their deployment. Each of the main parameters discussed above have a direct link to the perceived value of these options. As a result, they affect the propensity of the actors to select any one of them. Table 2 summarizes the perspectives of the aforementioned actors.

Table 2. The actors' perceptions in a power market. We summarize the perspectives of the aforementioned actors for the case of the power market. We apply the conceptual framework outlined in Section 2 in the power market and demonstrate the workability of the approach proposed here.

\begin{tabular}{|c|c|c|c|c|c|}
\hline Actors & Goals & Threats & $\begin{array}{l}\text { Available } \\
\text { Options }\end{array}$ & $\begin{array}{l}\text { Criteria for } \\
\text { Option } \\
\text { Selection }\end{array}$ & $\begin{array}{l}\text { Factors Affecting } \\
\text { Option Value }\end{array}$ \\
\hline \multirow{3}{*}{$\begin{array}{l}\text { Providers of } \\
\text { centralized } \\
\text { power }\end{array}$} & \multirow{3}{*}{$\begin{array}{l}\text { Maximize profits } \\
\text { Expand market } \\
\text { share } \\
\text { Minimize } \\
\text { liquidity risk }\end{array}$} & \multirow{3}{*}{$\begin{array}{l}\text { Reduction in } \\
\text { electricity demand } \\
\text { Increase in RES-E } \\
\text { generation with } \\
\text { priority grid access } \\
\text { Increase in price } \\
\text { spreads between } \\
\text { competitive fuels }\end{array}$} & $\begin{array}{l}\text { Increase } \\
\text { natural } \\
\text { gas-fueled } \\
\text { generation }\end{array}$ & $\begin{array}{l}\text { Relative } \\
\text { profitability }\end{array}$ & Fuel price spreads \\
\hline & & & $\begin{array}{l}\text { Increase } \\
\text { coal-fueled } \\
\text { generation }\end{array}$ & $\begin{array}{l}\text { Relative } \\
\text { profitability }\end{array}$ & Fuel price spreads \\
\hline & & & $\begin{array}{l}\text { Disinvestment } \\
\text { in thermal } \\
\text { assets }\end{array}$ & $\begin{array}{l}\text { Absolute } \\
\text { profitability }\end{array}$ & $\begin{array}{l}\text { Profit margins } \\
\text { (spreads between } \\
\text { fuel and power price) } \\
\text { Residual demand }\end{array}$ \\
\hline \multirow[t]{2}{*}{$\begin{array}{l}\text { Providers of } \\
\text { decentralized } \\
\text { power }\end{array}$} & \multirow[t]{2}{*}{$\begin{array}{l}\text { Maximize profits } \\
\text { Minimize } \\
\text { liquidity risk }\end{array}$} & \multirow{2}{*}{$\begin{array}{l}\text { Regulatory changes } \\
\text { Unanticipated } \\
\text { decreases in financial } \\
\text { support }\end{array}$} & \multirow{2}{*}{$\begin{array}{l}\text { Investment in } \\
\text { decentralized } \\
\text { RES-E } \\
\text { generation }\end{array}$} & $\begin{array}{l}\text { Expected } \\
\text { profitability }\end{array}$ & $\begin{array}{l}\text { Levels of financial } \\
\text { support } \\
\text { Tariff size } \\
\text { Contract duration }\end{array}$ \\
\hline & & & & Perceived risk & $\begin{array}{l}\text { Pressure for } \\
\text { regulatory changes }\end{array}$ \\
\hline \multirow[t]{2}{*}{$\begin{array}{l}\text { System } \\
\text { operator }\end{array}$} & \multirow{2}{*}{$\begin{array}{l}\text { Well functioning } \\
\text { market } \\
\text { Capacity } \\
\text { adequacy }\end{array}$} & $\begin{array}{l}\text { Disinvestments in } \\
\text { backup capacity }\end{array}$ & $\begin{array}{l}\text { Increase } \\
\text { capacity } \\
\text { payments }\end{array}$ & $\begin{array}{l}\text { System } \\
\text { reliability }\end{array}$ & $\begin{array}{l}\text { Magnitude of RES-E } \\
\text { offsetting } \\
\text { dispatchable } \\
\text { generation } \\
\text { Level of flexibility } \\
\text { needed for system } \\
\text { reliability }\end{array}$ \\
\hline & & $\begin{array}{l}\text { Increased fiscal } \\
\text { deficit }\end{array}$ & $\begin{array}{l}\text { Increase retail } \\
\text { prices }\end{array}$ & $\begin{array}{l}\text { Political and } \\
\text { social } \\
\text { feasibility }\end{array}$ & $\begin{array}{l}\text { Macroeconomic } \\
\text { conditions } \\
\text { Public discourse } \\
\text { regarding RES-E }\end{array}$ \\
\hline
\end{tabular}




\section{Conclusions}

This article presented a method for generating relevant policy scenarios by focusing on the actor-contingent elements of the scenarios, i.e., the developments that are within the power sphere of system actors to change or bring about, if they so choose. Overall, an efficient method based on the identification of key actors was presented here to speed up the scenario generation process. The applicability of our methodology has been demonstrated for the case of the Greek power market in light of the challenges that are related to the issues of generation capacity adequacy and the increased fiscal deficit. The strategic implications of the proposed approach concern the demonstration of the benefits from adopting a policy assessment methodology that focuses on stakeholder expectations and interactions.

The merit of the proposed approach stems from the fact that it regards policy design and evaluation as an exercise that affects stakeholders' expectations and behavior. As a consequence, it facilitates policy design by shedding light on the conditions that constitute threats or opportunities for the realization of a policy's goals. The strength of this approach lies in its ability to incorporate the stakeholders' opinions and perceptions, and thus to avoid the normative approach of modeling the stakeholders' behavior based on preconceived notions of what matters to them and how they weigh different future outcomes.

Successful policies in the power sector acknowledge the power system's inertia created by vested and conflicting interests of the involved actors and aim at deriving a path of least resistance towards the achievement of their policy goals. The proposed methodology is a facilitative tool for designing such policies. It can derive scenarios that actually matter for the success or failure of a given policy.

The methodology is not limited to a specific model or modeling approach. The only requirement is the ability to derive the expected behavior of different actors depending on their rules and criteria as well as the state of their environment.

Furthermore, the proposed approach can be combined with other widely used approaches for scenario generation such as backcasting. The energy infrastructure is a complex and dynamic socio-technical system. As such, its future evolution cannot be accurately predicted regardless of the regulatory forces in effect. This is because future events are caused by complex interactions between other precursors. They are not always the relevant ones. This renders the prediction of causal chains impossible (law of unintended consequences).

Further research stemming from the experience of the methodology includes possible ways of integrating the method with power market models that do not explicitly incorporate an actor-oriented component but are nevertheless widespread. These include cost-minimization models. A possible direction for this research can be found in the redefinition of cost. Apart from the investment and operation cost, an energy system sustains a cost that reflects the inertia of the actors to follow the (otherwise) least-cost path due to conflicting interests and unaccounted risks.

Acknowledgments: The author would like to thank the European Commission Directorate General for Research and Innovation for supporting the research activity APRAISE (Assessment of Policy Interrelationships and Impacts on Sustainability in Europe) Grant agreement 283121 and the partners of the APRAISE consortium who have contributed to the successful implementation of this project.

Conflicts of Interest: The author declares no conflict of interest.

\section{References}

1. Groves, D.G.; Lempert, R.J. A new analytic method for finding policy-relevant scenarios. Glob. Environ. Chang. 2007, 17, 73-85. [CrossRef]

2. Wright, G.; Goodwin, P. Decision making and planning under low levels of predictability: Enhancing the scenario method. Int. J. Forecast. 2009, 25, 813-825. [CrossRef]

3. Slovic, P.; Fischhoff, B.; Lichtenstein, S. Cognitive Processes and Societal Risk Taking. In Cognition and Social Behavior; Carroll, J.S., Payne, J.W., Eds.; Lawrence Erlbaum Associates: Potomac, MD, USA, 1976; pp. 177-178. 
4. Hughes, N.; Strachan, N.; Gross, R. The structure of uncertainty in future low carbon pathways. Energy Policy 2013, 52, 45-54. [CrossRef]

5. Borjeson, L.; Hojer, M.; Dreborg, K.; Ekvall, T.; Finnveden, G. Scenario types and techniques: Towards a user's guide. Futures 2006, 38, 723-739. [CrossRef]

6. Van Notten, P.W.F.; Rotmans, J.; van Asselt, M.B.A.; Rothman, D.S. An updated scenario typology. Futures 2003, 35, 423-443. [CrossRef]

7. Hughes, N. Towards improving the relevance of scenarios for public policy questions: A proposed methodological framework for policy relevant low carbon scenarios. Technol. Forecast. Soc. Chang. 2013, 80, 687-698. [CrossRef]

8. Bots, P.W.G.; van Twist, M.J.W.; van Duin, J.H.R. Designing a power tool for policy analysts: Dynamic actor network analysis. In Proceedings of the 32nd Hawaii International Conference on System Sciences, Los Alamitos, CA, USA, 1999.

9. Varho, V.; Tapio, P. Combining the qualitative and quantitative with the Q2 scenario technique-The case of transport and climate. Technol. Forecast. Soc. Chang. 2013, 80, 611-630. [CrossRef]

10. Papadelis, S.; Flamos, A.; Androulaki, S. Setting the framework for a Business Strategy Assessment Model. Int. J. Energy Sect. Manag. 2012, 6, 488-517. [CrossRef]

11. Kwakkel, J.H.; Auping, W.L.; Pruyt, E. Dynamic scenario discovery under deep uncertainty: The future of copper. Technol. Forecast. Soc. Chang. 2013, 80, 789-800. [CrossRef]

12. McFadden, D.L. Conditional logit analysis of qualitative choice behaviours. In Frontiers in Econometrics; Zarembka, P., Ed.; Academic Press: New York, NY, USA, 1974; pp. 105-142.

13. Prokopczuk, M.; Rachev, S.T.; Schindlmayr, G.; Truck, S. Quantifying risk in the electricity business: A RAROC-based approach. Energy Economics 2007, 29, 1033-1049. [CrossRef]

14. Renewable Energy: Moving towards a low carbon economy. Available online: http://ec.europa.eu/energy/ en/topics/renewable-energy (accessed on 16 November 2015).

15. 2030 Energy Strategy. Available online: http://ec.europa.eu/energy/en/topics/energy-strategy/2030energy-strategy (accessed on 16 November 2015).

16. Spyridaki, N.-A.; Banaka, S.; Flamos, A. Evaluating public policy instruments in the Greek building sector. Energy Policy 2016, 88, 528-543. [CrossRef]

17. Papadelis, S.; Stavrakas, V.; Flamos, A. What do capacity deployment rates tell us about the efficiency of RES-E support measures in Greece? Energies 2016, 9. [CrossRef]

18. Masini, A.; Menichetti, E. The impact of behavioral factors in the renewable energy investment decision making process: Conceptual framework and empirical findings. Energy Policy 2012, 40, 28-38. [CrossRef] 